\title{
Application of right bronchial blocker under artificial pneumothorax in thoracoscopic enucleation of oesophageal leiomyoma
}

\section{Luo Zhao}

Peking Union Medical College Hospital

Chao Gao

Peking Union Medical College Hospital

Jia He

Peking Union Medical College Hospital

\section{Zhijun Han}

Peking Union Medical College Hospital

\section{Li Li ( $\sim$ lili4037@pumch.cn )}

Peking Union Medical College Hospital https://orcid.org/0000-0001-7235-8050

\section{Research Article}

Keywords: Oesophageal leiomyoma, Enucleation, Video-assisted thoracoscopy, Artificial pneumothorax, Bronchial blocker

Posted Date: September 20th, 2021

DOl: https://doi.org/10.21203/rs.3.rs-907880/v1

License: (1) This work is licensed under a Creative Commons Attribution 4.0 International License. Read Full License 


\section{Abstract \\ Background}

Oesophageal leiomyomas are one of the most common benign oesophageal tumours. This study summarized and analysed the clinical experience of thoracoscopic enucleation of oesophageal leiomyoma.

\section{Methods}

A total of 36 patients who underwent thoracoscopic enucleation of oesophageal leiomyoma at Peking Union Medical College Hospital between 2014 and 2020 were retrospectively analysed. Fifteen patients received single-lumen endotracheal intubation combined with a right bronchial blocker (SLET-B group), and twenty-one patients received double-lumen endotracheal intubation (DLET group). Clinical data, surgical variables, and postoperative complications were analysed and compared.

\section{Results}

The average tumour size in all patients was $4.31 \pm 1.96 \mathrm{~cm}$. The average tumour size among symptomatic patients was significantly larger than that among asymptomatic patients $(5.08 \pm 2.02 \mathrm{vs}$ $3.71 \pm 1.72, P<0.05)$. Patients in the SLET-B group had a significantly larger average tumour size than patients in the DLET group $(5.39 \pm 2.13$ vs $3.54 \pm 1.42, \mathrm{P}<0.05)$. The SLET-B group had a significantly shorter operation time and shorter total hospital stay than the DLET group. No mucosal injury, conversion to thoracotomy, or other operative complications occurred in the SLET-B group. In the follow-up, no recurrence, dysphagia, or regurgitation was found in any of the patients.

\section{Conclusions}

Compared with traditional double-lumen intubation, artificial pneumothorax-assisted single-lumen endotracheal intubation combined with a bronchial blocker for thoracoscopic oesophageal leiomyoma enucleation can achieve complete removal of larger tumours, with fewer complications and shorter hospital stays.

\section{Introduction}

Oesophageal leiomyomas are the most common benign oesophageal tumours, accounting for approximately $70 \%-80 \%$ of oesophageal submucosal tumours (1). In recent years, video-assisted thoracoscopic enucleation of oesophageal leiomyoma has been shown to have better postoperative recovery than the thoracotomy approach (2). Compared with double-lumen endotracheal intubation anaesthesia, single-lumen endotracheal intubation combined with a bronchial blocker under artificial 
pneumothorax is a new type of anaesthetic technology. Artificial pneumothorax achieves better lung collapse and surgical field exposure and decreases blood loss, which are more convenient for tumour enucleation with less morbidity (3). This study retrospectively analysed a total of 36 patients diagnosed with oesophageal leiomyoma undergoing thoracoscopic surgery at Peking Union Medical College Hospital from 2014 to 2020. We present surgical outcomes of video-assisted thoracoscopic enucleation of oesophageal leiomyoma and evaluate the differences between traditional double-lumen endotracheal intubation and single-lumen endotracheal intubation combined with a bronchial blocker under artificial pneumothorax.

\section{Methods}

A total of 36 patients who underwent thoracoscopic enucleation of oesophageal leiomyoma by $\mathrm{Dr}$. Li at Peking Union Medical College Hospital from 2014 to 2020 were retrospectively selected. All patients were diagnosed with oesophageal leiomyoma by postoperative pathology, and the tumour location was evaluated by gastroscopy, upper gastrointestinal angiography and enhanced computed tomography of the chest and abdomen. Fifteen patients received single-lumen endotracheal intubation combined with a right bronchial blocker under artificial pneumothorax (the SLET-B group, September 2017 to December 2020), and twenty-one patients received traditional double-lumen endotracheal intubation (the DLET group, January 2014 to August 2017). The independent medical ethical committee of the Peking Union Medical College Hospital approved this study and all the patients signed extensive informed consent forms.

Anaesthetic and surgical procedures

All patients underwent a right thoracoscopic side approach, and a levin tube was placed before the operation. General anaesthesia was adopted in all patients. In the SLET-B group, a 7-Fr or 7.5-Fr singlelumen endotracheal tube was inserted, and a bronchial blocker was inserted into the right main bronchus under the guidance of a fibre bronchoscope. The patient was arranged in a left semi-prone position inclined 45 degrees. Artificial pneumothorax was created by $\mathrm{CO}_{2}$ insufflation with a pressure of $8 \mathrm{mmHg}$. In the DLET group, a left double-lumen endobronchial intubation was inserted. The parameters of the anaesthetic machine and anaesthetic drugs were the same as those in the SLET-B group.

In the operation, after the tumour was detected, the muscular layer of the oesophagus was opened by a coagulating hook. The tumour was separated from the muscular layer, carefully protecting the mucosa from injuries. After tumour enucleation, the muscular layer and the parietal pleura were closed using continuous $3-0$ V-loc stitches. The resected tumour was placed in a bag and removed from the chest. Air inflation by a levin tube was used to confirm whether there was oesophageal mucosal injury. If mucosal injury was found, the oesophageal mucosa was sutured by interrupted absorbable $3-0$ stitches. A 28French thoracic drain was left in the right chest. If no oesophageal mucosa injury was found during the operation, the levin tube was removed by the first day after the operation, and the oral diet was resumed the second day. If mucosal injury was found and repaired during the operation, patients received nothing 
by mouth with total enteral nutrition for 7 days, oesophagography was performed to confirm mucosal integrity, and the levin tube was removed after confirmation. The thoracic drainage tube was removed after drainage was less than $100 \mathrm{ml}$ and there was no air leak after oral diet feeding.

Variables collected

We collected data on the baseline characteristics and surgical and postoperative characteristics in this study.

\section{Statistical analysis}

Analysis was performed using Statistical Product and Service Solutions 22.0 statistical software. The continuous variables are expressed as the means $(x \pm s)$ or medians (P25, P75). We use Student's t-test or nonparametric test to compare the means between groups according to the normal distribution test (K-S test). The chi-squared test was used to compare the frequencies of the categorical variables data. $P$ value $<0.05$ were considered significant.

\section{Results}

Patient characteristics are shown in Table 1. There were 23 men and 13 women, with an average age of $43.67 \pm 10.55$ years. The majority of the tumours arose in the middle (19/36 [52.8\%]). Clinical symptoms were found in 16 patients, and 20 (55.6\%) patients were asymptomatic, with their tumours discovered incidentally by routine physical examination. The most common symptom that patients reported was dysphagia (10/36 [27.8\%]). Most patients had chronic symptoms persisting for months to years before surgical management. The average tumour size in all patients was $4.31 \pm 1.96 \mathrm{~cm}$. Among symptomatic patients, the average tumour size was $5.08 \pm 2.02 \mathrm{~cm}$, compared with an average tumour size of $3.71 \pm$ $1.72 \mathrm{~cm}$ in asymptomatic patients $(P=0.035)$. 
Table 1

Baseline characteristics. ( ${ }^{\star}$ Comparison between the SLET-B group and DLET group, ** Comparison between patients without symptoms and patients with symptoms)

\begin{tabular}{|c|c|c|c|c|}
\hline Variables & $\begin{array}{l}\text { Total } \\
(\mathrm{N}=36)\end{array}$ & $\begin{array}{l}\text { SLET-B group }(\mathrm{N}= \\
15)\end{array}$ & $\begin{array}{l}\text { DLET group }(\mathrm{N}= \\
21)\end{array}$ & $\begin{array}{l}\mathrm{P} \\
\text { value* }\end{array}$ \\
\hline Age (years) & $\begin{array}{l}43.67 \pm \\
10.55\end{array}$ & $45.2 \pm 8.89$ & $42.57 \pm 11.68$ & 0.469 \\
\hline Sex & & & & 0.681 \\
\hline Male & $23(63.9 \%)$ & 9 & 14 & \\
\hline Female & $13(36.1 \%)$ & 6 & 7 & \\
\hline Tumour location & & & & 0.803 \\
\hline Upper & $8(22.2 \%)$ & 4 & 4 & \\
\hline Middle & $19(52.8 \%)$ & 7 & 12 & \\
\hline Lower & $9(25 \%)$ & 4 & 5 & \\
\hline Presenting symptoms & & & & 0.923 \\
\hline Asymptomatic & $20(55.6 \%)$ & 8 & 12 & \\
\hline Dysphagia & $10(27.8 \%)$ & 5 & 5 & \\
\hline Regurgitation & $3(8.3 \%)$ & 1 & 2 & \\
\hline Chest discomfort & $3(8.3 \%)$ & 1 & 2 & \\
\hline Time to surgery (months) & $2(2,7.5)$ & $2(2,3)$ & $3(1.5,9.5)$ & 0.334 \\
\hline \multicolumn{5}{|l|}{ Tumour size (cm) } \\
\hline All patients & $4.31 \pm 1.96$ & $5.39 \pm 2.13$ & $3.54 \pm 1.42$ & 0.004 \\
\hline $\begin{array}{l}\text { Patients without } \\
\text { symptoms }\end{array}$ & $3.71 \pm 1.72$ & & & $0.035^{\star \star}$ \\
\hline Patients with symptoms & $5.08 \pm 2.02$ & & & \\
\hline
\end{tabular}

Fifteen patients were assigned to the SLET-B group, and twenty-one patients were assigned to the DLET group. No significant differences were observed between the two groups in age, sex, or tumour location. Patients in the SLET-B group had a significantly larger average tumour size than patients in the DLET group ( $5.39 \pm 2.13 \mathrm{~cm}$ vs $3.54 \pm 1.42 \mathrm{~cm}, P=0.004)$. Surgical and postoperative characteristics are presented in Table 2. The SLET-B group had a significantly shorter operation time, shorter duration of chest tube and total hospital stay than the DLET group. No mucosal injury, conversion to thoracotomy, or other operative complications occurred in the SLET-B group. Two cases of mucosal injury occurred in the DLET group and were repaired during the operation. The patients were discharged from the hospital after 
conservative treatment. The period of follow-up was 6 months to 6 years. In the follow-up, no recurrence, dysphagia, or regurgitation was found in any of the patients.

Table 2

Surgical and postoperative characteristics. ( ${ }^{\star}$ Compared between SLET-B group and DLET group)

\begin{tabular}{|lllll|}
\hline Variables & Total & $\begin{array}{l}\text { SLET-B group }(\mathbf{N}= \\
\mathbf{1 5})\end{array}$ & $\begin{array}{l}\text { DLET group }(\mathbf{N}= \\
\mathbf{2 1})\end{array}$ & $\begin{array}{l}\mathbf{P} \\
\text { value* }\end{array}$ \\
\hline Operation time, min & $\mathbf{N}=\mathbf{3 6}$ & & $120(97.5,150)$ & 0.030 \\
\hline Estimated blood loss $(\mathrm{ml})$ & $27.5(20.50)$ & $25(20,50)$ & $30(20,50)$ & 0.812 \\
\hline Mucosal injury & $2(5.6 \%)$ & 0 & $2(9.5 \%)$ & 0.219 \\
\hline $\begin{array}{l}\text { Postoperative } \\
\text { complication }\end{array}$ & 0 & 0 & 0 & $\mathrm{NA}$ \\
\hline $\begin{array}{l}\text { Duration of chest tube } \\
\text { Total hospital stay (days) }\end{array}$ & $5.97 \pm 2.22$ & $2.47 \pm 0.52$ & $5.04 \pm 2.36$ & $<0.001$ \\
\hline
\end{tabular}

\section{Discussion}

Oesophageal leiomyomas are the most common benign tumours of the oesophagus. It has been reported that the disease mainly occurs in the middle part of the oesophagus, followed by the lower and upper parts of the oesophagus (4). The tumour grows slowly, and small oesophageal leiomyomas are usually asymptomatic. With the growth of the tumour, patients may present acid regurgitation, chest pain, dysphagia and dyspepsia. With the development of gastroscopy and ultrasonic gastroscopy technology, an increasing number of asymptomatic small oesophageal leiomyomas have been detected and treated (5). However, in symptomatic patients, oesophageal leiomyomas are usually larger, which increases the difficulty in treatment.

At present, surgical treatment is the preferred choice for oesophageal leiomyoma, and enucleation is widely accepted as an adequate treatment (6). However, surgical indications for oesophageal leiomyoma are still controversial. Oesophageal leiomyoma may grow gradually, which may lead to surrounding tissue compression and potential malignant transformation. It is also difficult to differentiate leiomyoma from stromal tumour and leiomyosarcoma before surgery. Therefore, it is suggested that once diagnosed, surgical treatment should be performed regardless of symptoms (7). Codipilly et al summarized the clinical data of 105 patients with submucosal tumours and found that small leiomyomas grew very slowly, with an average growth rate of $0.5 \mathrm{~mm}$ every 6 years (8). At the same time, the rate of dysphagia in patients with larger leiomyoma surgery was higher than that in the conservative observation group, indicating that the risk of digestive tract obstruction caused by larger leiomyoma is lower than that caused by scar stenosis after surgery. However, there are some shortcomings in this study, such as a high rate of loss to follow-up and retrospective design. In our study, the average size of the tumour was $4.31 \pm$ 
$1.96 \mathrm{~cm}$, and the proportion of symptomatic patients was 44.4\% (16/36). Therefore, we indicate surgical enucleation for patients with symptomatic or larger oesophageal leiomyomas (larger than $2 \mathrm{~cm}$ ), while patients with smaller and asymptomatic oesophageal leiomyomas could be observed and then treated when they were obviously enlarged or had the possibility of malignancy.

Surgery consists of enucleation of smaller tumours. Oesophageal resection is advocated for large lesions, circular tumours, or if the tumour is densely adhesive to the mucosa. Compared with traditional thoracotomy, video-assisted thoracoscopic surgery has the advantages of minimal scarring, less pain, better postoperative respiratory function with fewer perioperative respiratory complications, and an enhanced fast recovery. It is generally considered that a right thoracic approach is used for middle and upper oesophageal tumours, and a left thoracic approach is used for lower oesophageal tumours (9). In our study, all patients completed tumour resection through the right thoracic approach, indicating that the right thoracic approach can complete all operations. Traditional double-lumen endotracheal intubation can achieve single-lung collapse to provide enough surgical vision, but due to the complex intubation process, the incidence of intraoperative tube displacement is high, and there are many postoperative respiratory complications. Thoracoscopic surgery in the prone position has been adopted in the majority of minimally invasive surgeries for oesophagus because it is easy to mobilize the oesophagus (10). Single-lumen endotracheal intubation combined with a bronchial blocker under artificial pneumothorax has the following advantages: 1 . Single-lumen endotracheal intubation is relatively simple, and a bronchial blocker can provide an effective seal of the bronchus with minimal trauma to achieve singlelung ventilation. 2. Single-lumen endotracheal intubation causes less damage to the airway mucosa and respiratory tract, which can reduce postoperative pharyngeal discomfort or pain. 3. Artificial pneumothorax (8 $\mathrm{mmHg}$ ) can obtain good lung collapse, cause capillaries to collapse and reduce bleeding, maintain a better surgical field and reduce side injury. In our study, complete tumour enucleation was achieved in patients in the SLET-B group, with a larger average tumour size and no mucosal damage or other complications and a shorter postoperative hospital stay than patients in the DLET group.

Thoracoscopic operation in the prone position with artificial pneumothorax with $\mathrm{CO}_{2}$ insufflation may add merits to the conventional decubitus position.

Oesophageal mucosal injury is the most common complication, especially when the tumour is large and close to the oesophageal mucosa. According to the author's experience, the main operation approach should be designed based on the tumour location, such as the 4th or 5th intercostal space for high and middle thoracic oesophageal leiomyomas and the 6th or 7th intercostal space for lower thoracic oesophageal leiomyomas. Blunt dissection should be used to dissect the tumour, and energy instruments should be avoided near the oesophageal mucosa side to prevent intraoperative oesophageal mucosal injury. After the enucleation of the tumour, the mucosal wound should be carefully examined. Air inflation of the oesophagus through endoscopy or a Levin tube should be used to check the dissected area to confirm the integrity of the mucosa. Absorbable sutures should be used to repair the injured oesophageal mucosa. For large mucosal injuries, the mediastinal pleura should be used to cover the injured part after 
repair, and the levin tube should be reserved. After 7 days of fasting, upper oesophagography should be performed to determine whether the injury had healed.

According to previous research, carbon dioxide artificial pneumothorax under low pressure $(<8 \mathrm{mmHg})$ has no significant effect on respiration and circulation (11). In our study, we did not observe any respiratory or haemodynamic disorders perioperatively. Another disadvantage is the inability of continuous sucking of the operative field, which may cause difficulty in the haemostatic process and increase the operation time. In our study, however, the operation time was significantly shorter in the SLET-B group. Therefore, we believe that this shortcoming can be overcome through more experience with this surgical technique.

Nevertheless, several limitations in our study are noted. First, as our data were retrospectively collected, patient selection bias may exist even though baseline characteristics were comparable. The SLET-B group has only been applied since 2017, thus, more experience with surgical technique may contribute to a better outcome in this group. In addition, the sample size was small; thus, larger-scale studies, especially multicentre collaboration, are needed.

\section{Conclusions}

In conclusion, thoracoscopic enucleation of oesophageal leiomyomas is a feasible and safe procedure. Single-lumen endotracheal intubation combined with a bronchial blocker under artificial pneumothorax shows significant advantages in larger tumour enucleation and shortening the operating time and recovery time from the operation compared with double-lumen intubation.

\section{Abbreviations}

SLET-B: single-lumen endotracheal intubation combined with right bronchial occlusion; DLET: doublelumen endotracheal intubation

\section{Declarations}

\section{Ethics approval and consent to participate}

The authors are accountable for all aspects of the work in ensuring that questions related to the accuracy or integrity of any part of the work are appropriately investigated and resolved. The study was conducted in accordance with the Declaration of Helsinki (as revised in 2013). The study was approved by the independent medical ethical committee of the Peking Union medical College and all the patients signed extensive informed consents.

\section{Consent for publication}

Not applicable. 
Availability of data and materials

The datasets supporting the conclusions of this article are included within the article and its additional files.

\section{Competing interests}

Not applicable.

\section{Funding}

Not applicable.

\section{Authors' contributions}

LZ, LL performed the conception and design. LZ, LL analyzed and interpreted the patient data. LZ, CG, JH, $\mathrm{ZJH}, \mathrm{LL}$ drafted the manuscript and all authors read and approved the final manuscript.

\section{Acknowledgements}

Not applicable.

\section{References}

1. Mutrie CJ, Donahue DM, Wain JC, Wright CD, Gaissert HA, Grillo HC, et al. Esophageal leiomyoma: a 40-year experience. Ann Thorac Surg. 2005 Apr;79:1122-5. doi:10.1016/j.athoracsur.2004.08.029.

2. Shin S, Choi YS, Shim YM, Kim HK, Kim K, Kim J. Enucleation of esophageal submucosal tumors: a single institution's experience. Ann Thorac Surg. 2014;97:454-9.

doi:10.1016/j.athoracsur.2013.10.030.

3. Shichinohe T, Kato K, Ebihara Y, Kurashima Y, Tsuchikawa T, Matsumoto J, et al. Thoracoscopic enucleation of esophageal submucosal tumor by prone position under artificial pneumothorax by CO2 insufflation. Surg Laparosc Endosc Percutan Tech. 2014;24:e55-8. doi:10.1097/SLE.0b013e31828f71e3.

4. Choong CK, Meyers BF. Benign esophageal tumors: introduction, incidence, classification, and clinical features. Semin Thorac Cardiovasc Surg. 2003;15:3-8. doi:10.1016/s1043-0679(03)700355 .

5. Li QY, Meng Y, Xu YY, Zhang Q, Cai JQ, Zheng HX, et al. Comparison of endoscopic submucosal tunneling dissection and thoracoscopic enucleation for the treatment of esophageal submucosal tumors. Gastrointest Endosc. 2017 Sep;86(3):485-91. doi:10.1016/j.gie.2016.11.023.

6. Wang YX, Zhang J, Liu Y, Liu Y, Chu XY, Lu ZS, et al. Diagnosis and comprehensive treatment of esophageal leiomyoma: clinical analysis of 77 patients. Int Jn Clin Exp Med. 2015;8:17214-20. 
7. Jiang W, Rice TW, Goldblum JR. Esophageal leiomyoma: experience from a single institution. Dis Esophagus. 2013;26:167-74. doi:10.1111/j.1442-2050.2012.01345.x.

8. Codipilly DC, Fang H, Alexander JA, Katzka DA, Ravi K. Subepithelial esophageal tumors: a singlecenter review of resected and surveilled lesions. Gastrointest Endosc. 2018;87:370-7. doi:10.1016/j.gie.2017.07.043.

9. Ben-David K, Alvarez J, Rossidis G, Desart K, Caranasos T, Hochwald S. Thoracoscopic and Laparoscopic Enucleation of Esophageal Leiomyomas. J Gastrointest Surg. 2015;19:1350-4. doi:10.1007/s11605-015-2817-0.

10. Lin $M$, Shen $Y$, Wang $H$, Fang $Y$, Qian $C$, Xu S, et al. A comparison between two lung ventilation with $\mathrm{CO} 2$ artificial pneumothorax and one lung ventilation during thoracic phase of minimally invasive esophagectomy. J Thorac Dis. 2018;10:1912-8. doi:10.21037/jtd.2018.01.150.

11. Zhang Y, Duan R, Xiao X, Pan T. Minimally invasive esophagectomy with right bronchial occlusion under artificial pneumothorax. Dig Surg. 2015;32:77-81. doi:10.1159/000371747. 